\title{
Discussion on the Peak Shift of A-Ti Phase in Tion Nanostructured Coatings on Ti-6Al-4V Alloy
}

\author{
Linh Nguyen Thi Truc a,", Zhong-Tao Jiang ${ }^{\mathrm{c}}$, Jaegyu Kim ${ }^{\mathrm{b}}$, Seungbum Hong ${ }^{\mathrm{b}}$, Kwangsoo No ${ }^{\mathrm{b}}$ \\ ${ }^{a}$ Department of Chemistry, Ho Chi Minh City University of Pedagogy, Ho Chi Minh City, Viet Nam \\ ${ }^{\mathrm{b}}$ Korea Advanced Institute of Science and Technology, Department of Materials Science and Engineering, Daejeon, \\ South Korea \\ ${ }^{\mathrm{c}}$ Surface Analysis and Materials Engineering Research Group, School of Engineering and Information Technology, \\ Murdoch University, Murdoch, WA 6150, Australia \\ *Corresponding author: \\ Dr. Linh Nguyen Thi Truc, Department of Chemistry, Ho Chi Minh City University of Pedagogy, 280 An Duong \\ Vuong, Ward 4, District 5, Ho Chi Minh City (Postal code: 700000), Viet Nam, linhntt@ hcmup.edu.vn
}

\section{Abstract}

In this study, $\mathrm{TiO}_{2}$ nanostructured coatings on $\mathrm{Ti}-6 \mathrm{~A}-4 \mathrm{~V}$ alloys were fabricated by two methods: $\mathrm{H}_{2} \mathrm{O}_{2}$ oxidation and $\mathrm{RF}$ sputtering. In the annealing temperature range of $25^{\circ} \mathrm{C}-500$ ${ }^{\circ} \mathrm{C}$, there were the peaks at $35^{\circ}, 37^{\circ}, 40^{\circ}$ and $52^{\circ}$ corresponding to $\{100\},\{002\},\{101\}$ and $\{102\}$ crystal planes of hcp structure of $\alpha$-Ti. At the annealing temperature of $600{ }^{\circ} \mathrm{C}$, there was the presence of peaks corresponding to crystal planes of anatase and rutile $\mathrm{TiO}_{2}$. The relative intensities of anatase and rutile phases of the sample fabricated by RF sputtering were 3.62 and $10.25 \%$, respectively; while those of the sample fabricated by $\mathrm{H}_{2} \mathrm{O}_{2}$ oxidation were 21.27 and $3.20 \%$, respectively (The relative intensity of $\alpha$-Ti phase was $100 \%$ ). The results investigated the peak shift of $\alpha$-Ti phase in $\mathrm{TiO}_{2} / \mathrm{Ti}-6 \mathrm{Al}-4 \mathrm{~V}$ nanostructured coatings fabricated by the two methods which was reasonably explained from the difference in the thermal expansion coefficients of $\mathrm{Ti}$ alloy and $\mathrm{TiO}_{2}$ components, as well as the difference in the ratio of anatase to rutile phases.

Keywords: Nanostructures; Crystallites; Physical vapor deposition processes; $\mathrm{TiO}_{2}$; Ti6Al4V alloy

\section{Introduction}

Ti-6A-4V ELI (Extra Low Interstitial) alloy (Grade 5, ASTM) has been widely used as a biomedical material in the medical industry due to its biocompatible (adj) and mechanical (adj) characteristics (noun) such as its good machinability, superior tensile, specific strength, fracture toughness, low weight ratio and corrosion resistance within the human body [1,2]. To achieve 
biocompatibility, osteoconductivity, and osseointegration, it is necessary to modify the surface of Ti-6Al-4V alloy by developing hydroxyapatite $\left(\mathrm{HAp}, \mathrm{Ca} 10\left(\mathrm{PO}_{4}\right)_{6}(\mathrm{OH})_{2}\right)$ coating on its surface [3-9]. HAp composite materials, which is a bonding interface to stimulate bone apatite and collagen production, improves bone anchorage due to osseointegration for long periods [10]. J. Dumbleton et al. [11] have proven that HAp coating should be in crystalline form which has an ability to provide a better substrate for the development of cells, to prevent the formation of adverse fibrous tissue. To increase the adhesion strength of HAp coating on the substrate, it should exhibit sub-layers between HAp coating and Ti-6Al-4V surface [12]. The addition of the sub-layers is expected to reduce a thermal expansion mismatch of the layers, as well as to achieve an abundance of surface hydroxyl and superoxide radicals groups, consequently, to achieve a surface free of cracks and a high adhesion of the modified surface to the substrate [13,14]. Kim H. W. et al. [15] investigated that the insertion of a $\mathrm{TiO}_{2}$ buffer layer was to improve the bonding strength between the HAp layer and Ti substrate, as well as to prevent the corrosion of the Ti substrate. The results reported in the publication [15] showed that the bonding strength of the $\mathrm{HAp} / \mathrm{TiO}_{2}$ double layer coating on $\mathrm{Ti}$ markedly increased, with the highest strength of the double layer coating at $55 \mathrm{MPa}$ after annealing at $500{ }^{\circ} \mathrm{C}$. Annealing the coating at the high temperature to keep the surface of hydroxyapatite stable, which is important for the interaction between hydroxyapatite substrate and bone tissue cells. Moreover, annealing the coating is to obtain nanostructured coatings with pre-determined structure, chemical and phase composition [16]. Other publications have also discussed the proper temperature to improve the strength and quality of the titanium-hydroxyapatite interface in the annealing temperature range of $500-750{ }^{\circ} \mathrm{C}$ [17-20]. However, at the high annealing temperature, the values of thermal expansion coefficients of Ti alloy and $\mathrm{TiO}_{2}$, as well as those of $\mathrm{HAp}$ and $\mathrm{TiO}_{2}$ should be concerned carefully. In this research, at the beginning, we focused on the difference in thermal expansion coefficients of $\mathrm{Ti}$ alloy and $\mathrm{TiO}_{2}$ components. According to the literature [21], the SI units of the coefficient of thermal expansion is $\mathrm{K}^{-1}$ and typical values for alloys are in the range of $10 \times 10^{-6}$ to $30 \times 10^{-6} \mathrm{~K}^{-1}$, and this value of $\mathrm{Ti}$ alloy is $8.70 \times 10^{-6} / \mathrm{K}$. The computed linear thermal expansion coefficient (TEC) of $\mathrm{TiO}_{2}$, which is similar with the experimental data, is $6.55 \times 10^{-6} \mathrm{~K}^{-1}$ [22]. Some original results determined the effect of the difference in the TEC values, as well as the preparation methods on the structure of $\mathrm{TiO}_{2}$ sub-layer on $\mathrm{Ti}-6 \mathrm{~A}-4 \mathrm{~V}$ alloy. The main aim of study is to investigate the peak shift of $\alpha$-Ti phase in $\mathrm{TiO}_{2} / \mathrm{Ti}-6 \mathrm{Al}-4 \mathrm{~V}$ 
nanostructured coatings fabricated by a controlled oxidation in hydrogen peroxide via RF magnetron sputtering technique.

\section{Material and methods}

The specimen used for this study was Ti-6Al-4V alloy (Gr 5, ASSTM 136, BAOJI TILEADER METAL PROCESSING CO., LTD) with a circular shape of $10.0 \mathrm{~mm}$ diameter and $1.0 \mathrm{~mm}$ thickness. The specimens were polished using the abrasive silicon carbide (SiC) paper up to 1200 grade. Final polishing was done using $0.02-0.25 \mu \mathrm{m}$ corundum grits (Struers APPaste SQ) and micro-cloth (40-72222, Buehler, Vibromet 2) to obtain a surface without scratch, followed by rinsing with distilled water and acetone in ultrasonic.

Preparation of $\mathrm{TiO}_{2}$ coating on Ti-6A-4V alloy via RF magnetron sputtering method: Using a $\mathrm{TiO}_{2}$ target (High Purity Chemicals Lab. Corp., Grade: 99.99\%) as the source material and Ar gas (99.99\%) as the sputtering gas. An RF generator was used at a frequency of $13.56 \mathrm{MHz}$ and a power of $100 \mathrm{~W}$. Ar gas was then introduced into the vacuum chamber by a mass flow controller at $50 \mathrm{sccm}$ and kept at $5.0 \times 10^{-3} \mathrm{mbar}$ as the total pressure. Before the deposition of the samples, the chamber was kept in the pre-sputtering regime for 10 min (shutter closed) to remove contaminations on the target surface in order to stabilize the deposition parameters. Ti$6 \mathrm{Al}-4 \mathrm{~V}$ surfaces were fixed onto the substrate holder which was centrally positioned in parallel just above the source material with a target- to-substrate distance of $60 \mathrm{~mm}$. The deposition time was 2 hours.

Converting Ti-6Al-4V surface to $\mathrm{TiO}_{2} / \mathrm{Ti}-6 \mathrm{Al}-4 \mathrm{~V}$ by the controlled oxidation in hydrogen peroxide: Ti-6Al-4V after polishing were subjected to oxidation in $30 \%$ solution of $\mathrm{H}_{2} \mathrm{O}_{2}$ (Purity Chemicals Lab, Korea) at $70^{\circ} \mathrm{C}$ for 48 hours.

The $\mathrm{TiO}_{2}$ nanostructured coatings on $\mathrm{Ti}-6 \mathrm{~A}-4 \mathrm{~V}$ alloy were annealed in a vacuum furnace at 25 Torr and the rate of temperature increase of $10^{\circ} \mathrm{C} / \mathrm{min}$, kept at the highest temperature (400, 500 and $600^{\circ} \mathrm{C}$ ) for 2 hours and cooled freely down to the room temperature.

The structure and phase composition of the surfaces were investigated via X-ray powder diffraction (XRD, Rigaku Ultima JV, Japan) with $\mathrm{Cu} K \alpha$ radiation $(\lambda=1.540 \AA$ ), the acquisition time of $4^{\circ}$ per minute, and the step size of 0.01 . 


\section{Results and discussion}

Fig. 1 displays that in the annealing temperature range of $25^{\circ} \mathrm{C}$ to $500{ }^{\circ} \mathrm{C}$, there were only four diffraction peaks at $35^{\circ}, 37^{\circ}, 40^{\circ}$ and $52^{\circ}$ (symbolized as $\boldsymbol{\square}$ ) corresponding to $\{100\}$, $\{002\},\{101\}$ and $\{102\}$ crystal planes of hexagonal close packed (hcp) structure of $\alpha-\mathrm{Ti}$, respectively (JCPDS database 44-1294). At the annealing temperature of $600{ }^{\circ} \mathrm{C}$, it can be observed the presence of two extra peaks at $25.2^{\circ}$ and $47.9^{\circ}$ (symbolized as $\boldsymbol{\Delta}$ ) corresponding to $\{101\}$ and $\{200\}$ crystal planes of tetragonal structure of $\mathrm{TiO}_{2}$ anatase phase (JCPDS database 84-1286). In addition, the peaks of $\mathrm{TiO}_{2}$ rutile phase appeared at $27.4^{\circ}$ and $54.4^{\circ}$ (symbolized as $\Delta)$ corresponding to $\{110\}$ and $\{211\}$ crystal planes (JCPDS database 88-1175).

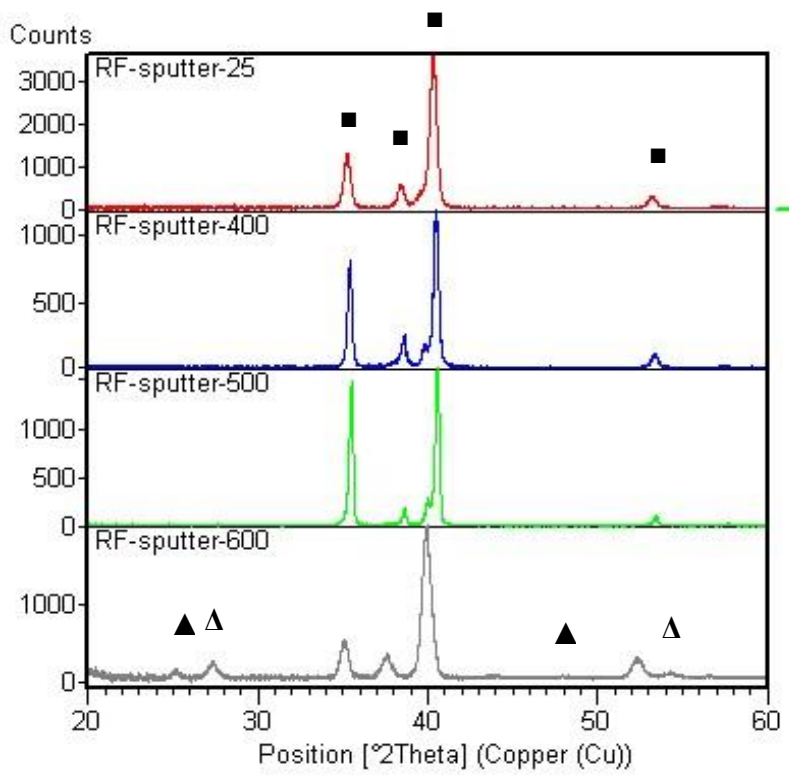

(a) RF sputtering

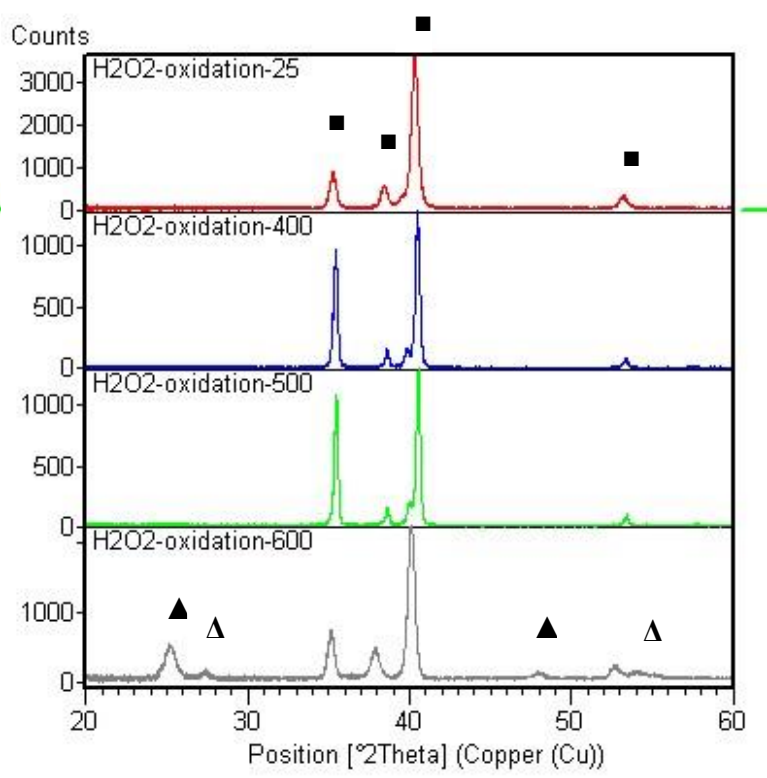

(b) $\mathrm{H}_{2} \mathrm{O}_{2}$ oxidation

Fig. 1: XRD patterns of $\mathrm{TiO}_{2} / \mathrm{Ti}-6 \mathrm{~A}-4 \mathrm{~V}$ samples annealed in the range of $25{ }^{\circ} \mathrm{C}$ to $600{ }^{\circ} \mathrm{C}$

Remarkably, the peak shift phenomenon of all four diffraction peaks of $\alpha$-Ti phase was observed in XRD pattern of $\mathrm{TiO}_{2} / \mathrm{Ti}-6 \mathrm{~A}-4 \mathrm{~V}$ alloy annealed at $600{ }^{\circ} \mathrm{C}$, while these peaks did not shift in all the cases of $\mathrm{TiO}_{2} / \mathrm{Ti}-6 \mathrm{~A}-4 \mathrm{~V}$ alloy annealed in the range of $25^{\circ} \mathrm{C}$ to $500{ }^{\circ} \mathrm{C}$, as well as those of Ti-6A-4V alloy annealed at $600{ }^{\circ} \mathrm{C}$. The central positions of these peaks shifted to lower 2-theta side, consequently, the corresponding $d$ spacing values of the reflections increased (Table 1). Changes in lattice spacing of titanium crystalline were presented in some publication as following: R. Montanaria et al. [28] investigated the effects of nitrogen and oxygen absorption 
on lattice expansion of Ti-6Al-4V by high-temperature $\mathrm{X}$-ray diffraction. After annealing this material at $600{ }^{\circ} \mathrm{C}$, the oxygen or nitrogen atoms may occupy in the octahedral interstices of (hcp) structure of $\alpha-\mathrm{Ti}$, which results in the expansion of cell volume and the changes in the ratio of cell parameters. According to the literatures [29, 30] mechanical and physical properties of titanium alloys strongly depend on interstitial elements at high temperature. The nature of the reinforcement/matrix interface plays a significant role in the stress transfer of the composites, thus influences the mechanical properties of composites.

Table 1: $d$ spacing values of the reflections $\{100\},\{002\},\{101\}$ and $\{102\}$ of $\alpha$-Ti existing in $\mathrm{TiO}_{2} / \mathrm{Ti}-6 \mathrm{~A}-4 \mathrm{~V}$ samples annealed at various temperatures

\begin{tabular}{|c|c|c|c|c|c|c|}
\hline \multirow{2}{*}{ hlk\} } & \multicolumn{5}{|c|}{ d spacing (nm) } \\
\cline { 5 - 7 } & $\mathbf{2 5}{ }^{\circ} \mathrm{C}$ & $\mathbf{4 0 0}{ }^{\circ} \mathrm{C}$ & $\mathbf{5 0 0}{ }^{\circ} \mathrm{C}$ & \multicolumn{3}{|c|}{$\mathbf{6 0 0}^{\circ} \mathrm{C}$} \\
\cline { 5 - 7 } & & & & Ti alloy & $\mathbf{H}_{2} \mathbf{O}_{2}$ oxidation & RF sputtering \\
\hline$\{100\}$ & 25.44 & 25.42 & 25.41 & 25.44 & 25.50 & 25.61 \\
\hline$\{002\}$ & 23.34 & 23.38 & 23.37 & 23.45 & 23.70 & 23.87 \\
\hline$\{101\}$ & 22.31 & 22.30 & 22.28 & 22.32 & 22.45 & 22.57 \\
\hline$\{102\}$ & 17.16 & 17.12 & 17.14 & 17.17 & 17.36 & 17.46 \\
\hline
\end{tabular}

In this study, oxygen and nitrogen elements may not exist in the coatings due to annealing in a vacuum furnace. Thus, the $\mathrm{TiO}_{2}$ film, which was crystallized in anatase and rutile phases, formed onto the surface of Ti-6A-4V alloy and affected on the structure of the original alloy as the temperature increased up to $600{ }^{\circ} \mathrm{C}$. In fact, the thermal expansion coefficient (TEC) of $\mathrm{Ti}$ alloy was $8.70 \times 10^{-6} / \mathrm{K}$ and that of $\mathrm{TiO}_{2}$ was $6.55 \times 10^{-6} \mathrm{~K}^{-1}$. The TEC, which is one of the structural parameters, was given as a reason in the increase of $\mathrm{d}$ spacing values of the reflections of $\mathrm{TiO}_{2} / \mathrm{Ti}-6 \mathrm{~A}-4 \mathrm{~V}$ alloy annealed at the phase transition temperature of $\mathrm{TiO}_{2}$. The $\mathrm{TEC}$ of $\mathrm{Ti}$ alloy is larger than that of $\mathrm{TiO}_{2}$, so the rate of contraction of $\mathrm{TiO}_{2}$ layer should be smaller than that of Ti substrate during cooling, which resulted in the lattice expansion.

Particularly, Table 1 also presents that the degree of lattice expansion of the sample fabricated by the controlled oxidation in hydrogen peroxide was less than that of the sample synthesized by the RF magnetron sputtering method. This result can be explained by the difference in the thermal expansion coefficients of anatase and rutile phases, as well as the difference in the ratio of the two phases in the samples fabricated by the different processes. To determine the relative ratios of anatase phase to rutile phase coexisting in $\mathrm{TiO}_{2} / \mathrm{Ti}_{6} \mathrm{Al} / \mathrm{V}$ 
samples, the strongest reflections for anatase and rutile phases were conveniently located at $25.2^{\circ}$ and $27.4^{\circ}$, after baseline correction (Fig. 2).

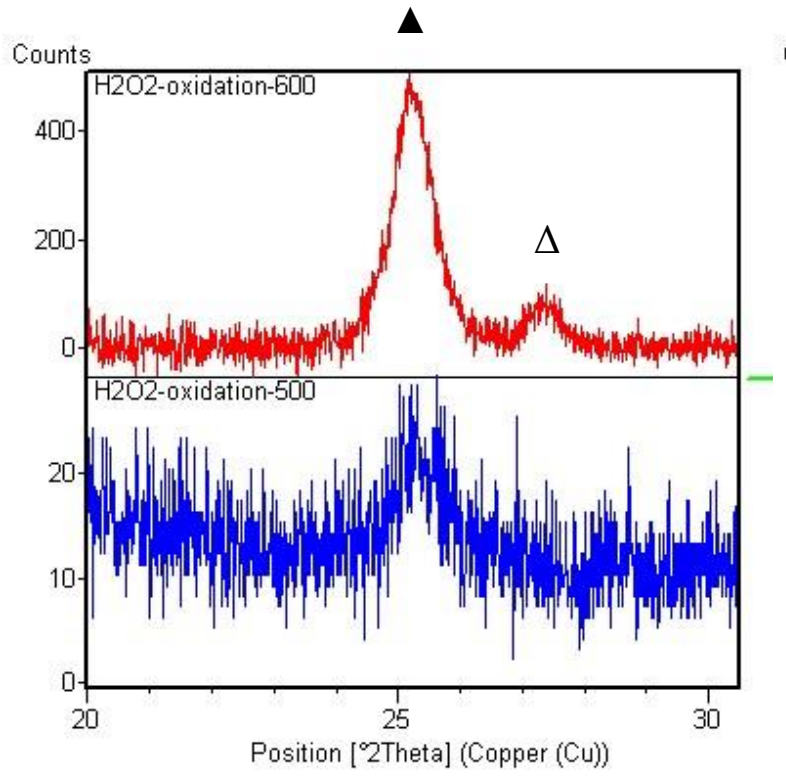

(a) $\mathrm{H}_{2} \mathrm{O}_{2}$ oxidation

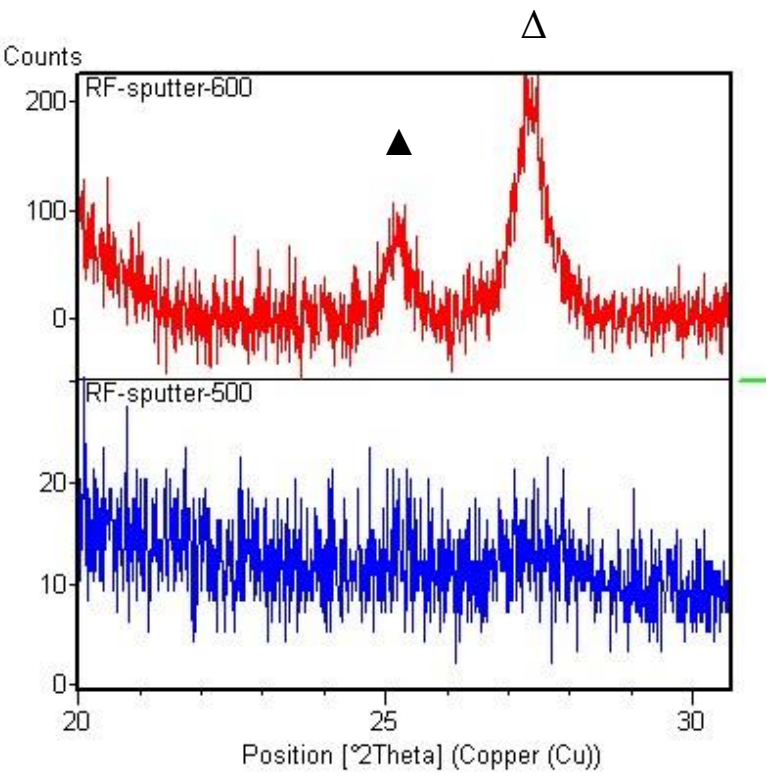

(b) RF sputtering

Fig. 2: The presence of the peaks in the 2-theta range of $20-30^{\circ}$ of the samples annealed at $500{ }^{\circ} \mathrm{C}$ and $600{ }^{\circ} \mathrm{C}$, where anatase phase is symbolized as $\boldsymbol{\Lambda}$, and rutile phase is symbolized as $\Delta$

Fig. 2 investigated the difference in the temperature of formation of anatase, rutile phases in the two fabrications, as well as in the ratio of anatase phase to rutile phase. Firstly, the anatase phase appeared in the sample fabricated by the $\mathrm{H}_{2} \mathrm{O}_{2}$ oxidation after annealing at $500{ }^{\circ} \mathrm{C}$, while this phase did not appear in the sample fabricated by RF sputtering at the same annealing temperature. Moreover, the sample fabricated by RF sputtering had an amount of rutile phase increasing fast after annealing from 500 to $600{ }^{\circ} \mathrm{C}$. According to James's explanation (J. Ovenstone et al. [27]), the presence of a small amount of brookite phase contamination in the anatase resulted in rapid conversion to the rutile. In case of the sample fabricated by the controlled oxidation in hydrogen peroxide, the amount of anatase phase was higher than that of rutile phase, while the sample fabricated by the RF magnetron sputtering method had an opposite ratio. This result means $\mathrm{TiO}_{2}$ coatings sputtered via $\mathrm{RF}$ sputtering may contain a small amount of brookite phase, however, that was not confirmed by XRD examination. Secondly, the difference in the ratio of anatase phase to rutile phase was identified due to the relative intensity $(\%)$ of the peaks (Table 2). 
Table 2: Data of the peaks at $25.2^{\circ}$ and $27.4^{\circ}$ of the samples annealed at $500{ }^{\circ} \mathrm{C}$ and $600{ }^{\circ} \mathrm{C}$

\begin{tabular}{|c|c|c|c|c|c|}
\hline \multirow{2}{*}{ Sample } & Phase & $\begin{array}{c}\text { Position } \\
{\left[{ }^{\circ} \text { 2Th.] }\right.}\end{array}$ & $\begin{array}{c}\text { FWHM } \\
{\left[{ }^{\circ} \text { 2Th.] }\right.}\end{array}$ & $\begin{array}{c}\text { Relative } \\
\text { Intensity [\%] }\end{array}$ & $\begin{array}{c}\text { Crystallite } \\
\text { size (nm) }\end{array}$ \\
\hline \multirow{5}{*}{ RF-sputter-600 } & Anatase & 25.22 & 0.472 & 3.62 & 16.2 \\
\cline { 2 - 6 } & Rutile & 27.38 & 0.551 & 10.25 & 13.8 \\
\hline \multirow{3}{*}{ Oxidation-600 } & $\alpha-\mathrm{Ti}$ & 39.92 & 0.708 & 0.629 & 12.2 \\
\cline { 2 - 6 } & Anatase & 25.18 & 0.629 & 3.20 & 12.1 \\
\cline { 2 - 6 } & Rutile & 27.42 & 0.629 & 100 & - \\
\hline
\end{tabular}

Table 2 also showed the crystallite sizes of the anatase and rutiles phases coexisting in $\mathrm{TiO}_{2} / \mathrm{Ti6A14V}$ samples. In case of the sample fabricated by the oxidation, the widths of peaks at $25.2^{\circ}$ and $27.4^{\circ}$ for anatase and rutile phases, respectively, were practically the same, so anatase and rutile crystallites had the same size. While the sample fabricated by RF sputtering had the sizes of anatase and rutile crystallites were slightly higher. The difference in crystallite sizes calculated from XRD data was appropriate to that in particle sizes observed from SEM images (Fig. 3). Thus, the degree of lattice expansion of $\alpha$-Ti phase in the sample fabricated by the $\mathrm{H}_{2} \mathrm{O}_{2}$ oxidation was less than that in the sample fabricated by the RF sputtering because of two reasons: First, the TEC of $\mathrm{TiO}_{2}$ anatase was smaller than that of $\mathrm{TiO}_{2}$ rutile in the same condition [31]. Second, the amount of anatase phase was higher than that of rutile phase in the case of the sample fabricated via $\mathrm{H}_{2} \mathrm{O}_{2}$ oxidation process.

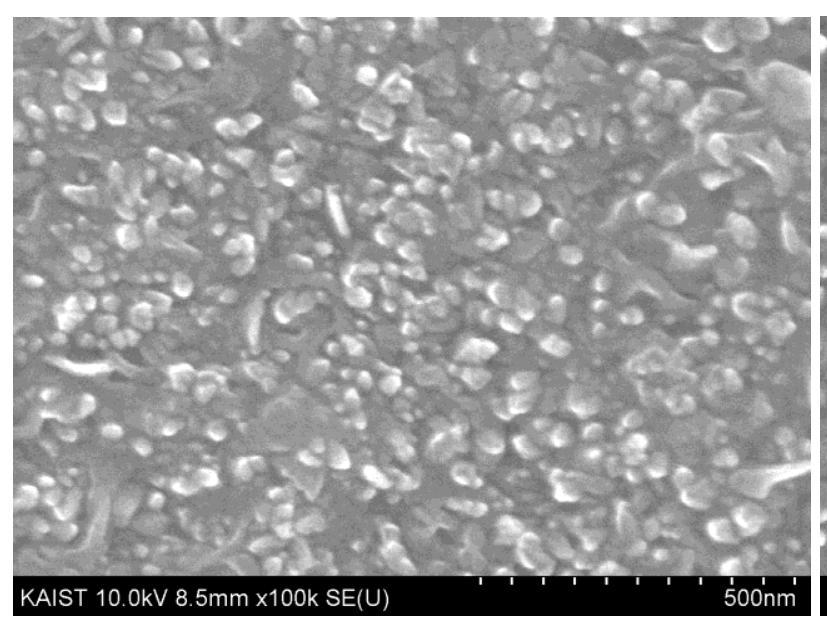

(a) $\mathrm{H}_{2} \mathrm{O}_{2}$ oxidation

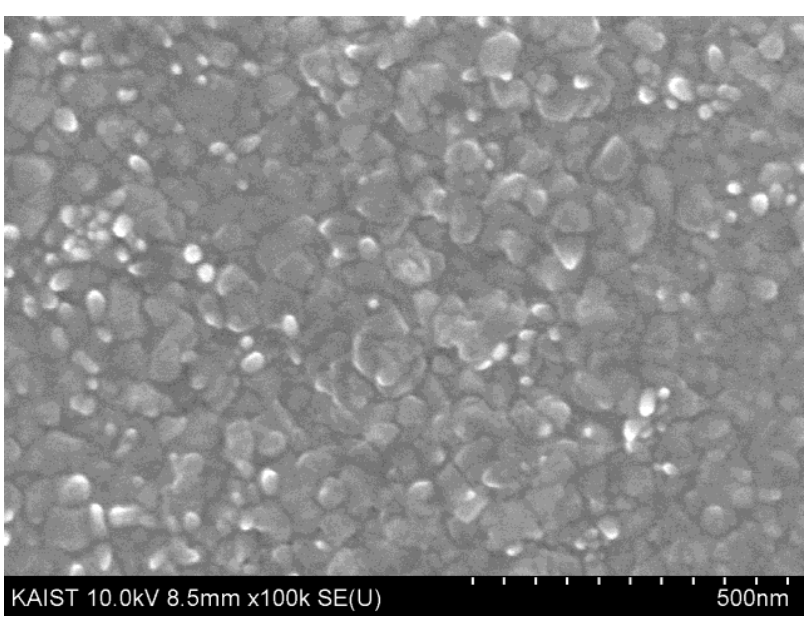

(b) RF sputtering

Fig. 3: SEM images of the samples annealed at $600{ }^{\circ} \mathrm{C}$

\section{Conclusion}


In summary, we successfully synthesized $\mathrm{TiO}_{2}$ nanostructured coatings on Ti-6A-4V alloy by both $\mathrm{H}_{2} \mathrm{O}_{2}$ oxidation and RF sputtering. The results investigated the peak shift of the reflections $\{100\},\{002\},\{101\}$, and $\{102\}$ of $\alpha$-Ti existing in $\mathrm{TiO}_{2} / \mathrm{Ti}-6 \mathrm{~A}-4 \mathrm{~V}$ materials at the high annealing temperature. The relative intensities of anatase and rutile phases of the sample fabricated by RF sputtering were 3.62 and $10.25 \%$, respectively; while those of the sample fabricated by $\mathrm{H}_{2} \mathrm{O}_{2}$ oxidation were 21.27 and $3.20 \%$, respectively (The relative intensity of $\alpha$-Ti phase was $100 \%$ ). It is deduced that the difference in the thermal expansion coefficients of $\mathrm{Ti}$ alloy and $\mathrm{TiO}_{2}$ components, as well as the difference in the ratio of anatase to rutile phases were the main reason of changes in lattice spacing of $\alpha$-Ti phase.

\section{Author Contributions}

Linh Nguyen Thi Truc, Jaegyu Kim conducted the experiments and prepared the figures and tables. Kwangsoo No, Seungbum Hong contributed to data analysis and interpretation. Linh Nguyen Thi Truc and Zhong-Tao Jiang wrote the main manuscript text. All authors including Linh Nguyen Thi Truc, Jaegyu Kim, Zhong-Tao Jiang, Seungbum Hong, Kwangsoo No reviewed the manuscript.

\section{Additional Information}

Competing interests All authors declare no competing interests.

\section{Acknowledgement}

This research was supported by Small Grant Scheme (2017) of the SEIT, Murdoch University and by Basic Science Research Programs (No. 2015R1D1A1A01056983) through the NRF, Korea, funded by the Ministry of Education, and (No. 2018R1A2B6002194) through the NRF, Korea funded by the Ministry of Science and ICT.

\section{References}


[1] Morais L. S., Serra G. G., Muller C. A., Andrade L. R., Palermo E. F., Elias C. N., Meyers M., Titanium Alloy Mini-Implants for Orthodontic Anchorage: Immediate Loading and Metal Ion Release, Acta Biomaterialia, 3 (3) (2007), pp. 331-339

[2] C. N. Elias, J. H. C. Lima, R. Valiev, M. A. Meyers, Biomedical applications of titanium and its alloys, Volume 60, Issue 3, pp 46-49 (2008)

[3] Sandrini E, Giordano C, Busini V, Signorelli E, Cigada A., Apatite formation and cellular response of a novel bioactive titanium, J. Mater. Sci. Mater. Med. 18 (2007) 1225-1237

[4] Peng Yu, Fang Lu, Wenjun Zhu, Di Wang, Xiaojing Zhu, Guoxin Tan, Xiaolan Wang, Yu Zhang, Lihua Li, Chengyun Ning, Bio-inspired citrate functionalized apatite coating on rapid prototyped titanium scaffold, Appl. Surf. Sci. 313 (2014) 947-953

[5] C. Aparicio, D. Rodriguez, F. J. Gil, Variation of roughness and adhesion strength of deposited apatite layers on titanium dental implants, Mater. Sci. Eng. C 31 (2011) 320-324

[6] Dianying Chen, Eric H. Jordan, Maurice Gell, Mei Wei, Apatite formation on alkaline-treated dense $\mathrm{TiO}_{2}$ coatings deposited using the solution precursor plasma spray process, Acta Biomater. 4 (2008) 553-559

[7] Hae-Won Kim, Young-Hag Koh, Long-Hao Li, Sook Lee, Hyoun-Ee Kim, Hydroxyapatite coating on titanium substrate with titania buffer layer processed by sol-gel method, Biomaterials 25 (2004) 2533-2538

[8] A. Balamurugan, G. Balossier, J. Michel, J. M. F. Ferreira, Electrochemical and structural evaluation of functionally graded bioglass-apatite composites electrophoretically deposited onto Ti6Al4V alloy, Electrochim. Acta 54 (2009) 1192-1198

[9] M.Chellappa, U.Vijayalakshmi, Electrophoretic deposition of silica and its composite coatings on Ti-6Al-4V, and its in vitro corrosion behaviour for biomedical applications, Materials Science and Engineering C xxx (2016) Xxx-Xxx, in press

[10] Ravi Krishna Brundavanam, Zhong-Tao Jiang, Peter Chapman, Xuan-Thi Le, Nicholas Mondinos, Derek Fawcett, Gérrard Eddy Jai Poinern, Effect of dilute gelatine on the ultrasonic thermally assisted synthesis of nano hydroxyapatite, Ultrasonics Sonochemistry 18 (2011) 697703.

[11] Dumbleton J, Manley MT., Hydroxyapatite-coated prostheses in total hip and knee arthroplasty. Journal of Bone and Joint Surgery - Series A. 2004; 86(11): 2526-40 
[12] V. M. Ievlev, E. P. Domashevskaya, V. I. Putlyaev, Yu. D. Tret'yakov, S. M. Barinov, E. K. Belonogov, A. V. Kostyuchenko, M. I. Petrzhik, F. V. Kiryukhantsev-Korneev, Structure, elemental composition, and mechanical properties of films prepared by radio-frequency magnetron sputtering of hydroxyapatite. Glass Physics and Chemistry. 2008; 34(5):608-16

[13] Takemoto S, Yamamoto T, Tsuru K, Hayakawa S, Osaka A, Takashima S., Platelet adhesion on titanium oxide gels: effect of surface oxidation, Biomaterials 25 (2004) 3485-3492

[14] P Tengvall B Wälivaara J Westerling I Lundström, Stable titanium superoxide radicals in aqueous Ti-peroxy gels and Ti-peroxide solutions, J. Colloid Interface Sci. 143 (1991) 589592

[15] Kim HW, Koh YH, Li LH, Lee S, Kim HE, Hydroxyapatite coating on titanium substrate with titania buffer layer processed by sol-gel method, Biomaterials. 2004 Jun; 25(13):2533-8

[16] K. Van Dijk, H. G. Schaeken, J. C. G. Wolke, C. H. M. Maree, F. H. P. M. Habraken, J. Verhoeven, and J. A. Jansen, Influence of discharge power level on the properties of hydroxyapatite films deposited on Ti6A14V with RF magnetron sputtering, Journal of Biomedical Materials Research, Vol. 29, 269-276 (1995)

[17] A. Carradò, F. Perrin-Schmitt, Q.V. Le, M. Giraudel, C. Fischer, G. Koenig, L. Jacomine, L. Behr, A. Chalom, L. Fiette, A. Morlete, G. Pourroy, Nanoporous hydroxyapatite/sodium titanate bilayer on titanium implants for improved osteointegration, Dental Materials (2016)

[18] Mohammadi S, Esposito M, Hall J, Emanuelsson L, Krozer A, Thomsen P. Short-term bone response to titanium implants coated with thin radiofrequent magnetron-sputtered hydroxyapatite in rabbits. Clin Implant Dent Relat Res 2003; 5: 241-253

[19] Zhi xin Kang, Junyi Zhang, Lei Niu, A one-step hydrothermal process to fabricate superhydrophobic hydroxyapatite coatings and determination of their properties, Surface and Coatings Technology, Volume 334, 25 January 2018, Pages 84-89

[20] Rad AT, Novin M, Solati-Hashjin M, Vali H, Faghihi S., The effect of crystallographic orientation of titanium substrate on the structure and bioperformance of hydroxyapatite coatings, Colloids Surf B Biointerfaces 2013;103:200-8

[21] J D James, J A Spittle, S G R Brown and R W Evans, A review of measurement techniques for the thermal expansion coefficient of metals and alloys at elevated temperatures, Measurement Science and Technology 12 (2001) R1-R15 
[22] S.L.Tang, Y.R.Wang, Y.M.Gao, Q.L.Zheng, D.W.Yi, Theoretical study of mechanical and thermodynamic properties of titanium oxides $\mathrm{Ti}_{x} \mathrm{O}_{y}$, Materials Chemistry and Physics, 2018, In Press, Accepted Manuscript

[23] M. Karthega, N. Rajendran, Hydrogen peroxide treatment on Ti-6Al-4V alloy: A promising surface modification technique for orthopaedic application, Applied Surface Science, Volume 256, Issue 7, 15 January 2010, Pages 2176-2183

[24] Nishiguchi S, Nakamura T, Kobayashi M, Kim HM, Miyaji F, Kokubo T., The effect of heat treatment on bone-bonding ability of alkali-treated titanium. Biomaterials 1999; 20:491-500 [25] C.Guillén, J.Herrero, $\mathrm{TiO}_{2}$ coatings obtained by reactive sputtering at room temperature: Physical properties as a function of the sputtering pressure and film thickness, Thin Solid Films, Volume 636, 31 August 2017, Pages 193-199

[26] Jaspal Singh, Saif A.Khan, J.Shah , R. K. Kotnala, Satyabrata Mohapatra, Nanostructured $\mathrm{TiO}_{2}$ thin films prepared by RF magnetron sputtering for photocatalytic applications, Applied Surface Science, Volume 422, 15 November 2017, Pages 953-961

[27] James Ovenstone, and Kazumichi Yanagisawa, Effect of Hydrothermal Treatment of Amorphous Titania on the Phase Change from Anatase to Rutile during Calcination, Chem. Mater., 1999, 11 (10), pp 2770-2774

[28] R. Montanaria, G. Costanza, M.E. Tata, C. Testanib, Lattice expansion of Ti-6Al-4V by nitrogen and oxygen absorption, Materials characterization 59 (2008) 334 - 337

[29] Simbi DJ, Schully JC. The effect of residual interstitial elements and iron on mechanical properties of commercially pure titanium. Mater Lett 1996; 26:35-9

[30] Ouchi C, Iizumi H, Mitao S. Effects of ultra-high purification and addition of interstitial elements on properties of pure titanium and titanium alloys. Mater Sci Eng A 1998; 243: 186-95 [31] K. V. Krishna Rao, S. V. Nagender Naidu, Leela Iyengar, Thermal Expansion of Rutile and Anatase, Journal of the American Ceramic Socisty, Volume 53, Issue 3, 1970, 124-126 